\title{
Occupational Allergic Rhinitis in the Czech Republic - Situation in South Moravia Region
}

\author{
Petr Malenka \\ Department of Occupational Diseases, St. Anne's Hospital and Masaryk University, Brno \\ Czech Republic
}

\section{Introduction}

The author will describe in this chapter the definition, pathophysiology, ethiopathogenesis, complex diagnostic procedure and treatment of occupational allergic rhinitis. Then there will be provided an analysis of cases of occupational rhinitis which were diagnosed and notified as an occupational disease in southern Moravia from January 2004 to December 2006.

Allergic rhinitis can occur due to exposure to different allergens in the working environment. Occupational rhinitis symptoms occur during repeated exposure to an offending allergen. Symptoms of occupational rhinitis are the same as those associated with other types of rhinitis and include sneezing, itching, clear rhinorrhea, nasal congestion and nonpurulent discharge.

Criteria for evaluating rhinitis as an occupational disease: positive work history, there had been no nasal allergic disease before obtaining a job, proof of specific sensibilisation existence - exposure test, prick skin testing, IgE, nasal provoking test etc.

Worker with established occupational disease is not able to perform jobs in which he/she would be exposed to either the chemicals which he/she is proven to be hypersensitive or to respiratory pathogenic agents of any origin.

Allergic rhinitis often represents the initial phase of more serious disease such as asthma.

\section{Allergic rhinitis}

Allergic rhinitis is characterized by the International Consensus on the treatment of allergic rhinitis (Cauwenberge et al.,2000) by the following symptoms: itching in the nose, sneezing, watery rhinorrhoea and nasal obstruction. Headache, impaired smell, and conjunctivitis may occur as other symptoms.

Allergic rhinitis is the manifestation of allergy, IgE-mediated and associated with inflammatory cell infiltration of the nasal mucosa. An inflammation develops in the mucosa and it contributes to the formation of nasal symptoms and the development of nasal nonspecific hyperreactivity. Nasal mucosa responds to incentives in four ways. Congestion is based on the vasodilatation and increased vascular permeability. Itching and sneezing cause stimulation of sensory nerves. Secretion from the nose is the result of stimulation of the glands and increased vascular permeability. 


\subsection{Pathophysiology}

The inflammatory responses of upper respiratory tract are similar in nature to those in the lower airways. The main difference is that the deterioration in the nasal passage area lies in the changes in vascular tone (the predominant influence of vasodilatation and vascular filling capacity), whereas in the bronchi it leads to a significant contraction of smooth muscles.

The human upper respiratory tract (as opposed to experiments on rodents) does not respond to increasing vascular permeability of irritants. Neurological responses include central mechanisms (cholinergic) and local (axonic) neurogenic reflexes (Bascom et al, 1999). The emergence of rhinitis symptoms can generally be provoked by both allergens and irritants.

\subsection{Etiopathogenesis}

Inhaled allergens of external environment interact with specific IgE bound to mast cell receptor of nasal mucosa. After binding to allergen-specific $\operatorname{IgE}$ there are preformed mediators and newly developed mast cells released and after the release of cytokines it leads to the development of nasal inflammation. This inflammatory process is associated with endothelial cell activation and accumulation of eosinophils from the circulation into tissues.

In the epithelium of the nasal mucosa there are located not only mast cells and eosinophils, but also T lymphocytes, and basophils. Also epithelial cells are activated in case of allergic diseases and the mediators released from them contribute to the spread of symptoms of allergic rhinitis.

We distinguish the early phase, in which itching, sneezing, runny nose and nasal congestion dominate. The development of symptoms is associated with elevated levels of histamine, tryptase, devoid glandins, leukotrienes and kinins. These findings are a manifestation of mast cell degranulation.

The early phase is followed by a late phase, which reflects the activation of basophils. There is a late accumulation of eosinophils, activation of $\mathrm{T}$ lymphocytes and a rise of adhesive molecules on the surface of vascular epithelium. In addition to cellular processes and their regulations neural influence are applied. In addition to autonomic control of glandular secretion and nasal vascular tone, also non-adrenergic and non-cholinergic control in the nose is present.

Activation of sensory nerves and local release of mediators causes vasodilatation and enhance microvascular permeability through stimulation of local and axonic reflexes and modifications ganglion neurotransmission (Horwath,1999).

The late phase of chronic allergic rhinitis is clinically characterized by predominance of nasal blockade, impaired sense of smell and constant nasal hyperreactivity.

\subsection{The distribution of allergic rhinitis}

According to the new International consensus (Cauwenberge et al.,2000), allergic rhinitis can be divided into perennial, seasonal and professional.

Chronic rhinitis resulting in causal connection with the work may be associated not only with the immunopathological mechanism of formation - allergic rhinitis, but also with nonimmunological pathogenesis. In that case we speak about a non-allergic rhinitis. 


\section{Occupational rhinitis}

Definition of occupational rhinitis is a medico-legal term. Occupational allergic rhinitis is an allergic rhinitis, which has been objectively proved thar the cause or the major (predominant) cause of the disease is pollutant, or that the patient was exposed in their working environment. Professional diagnosis of rhinitis cannot be based only on anamnestic data and routine laboratory tests, but it must be properly objectified. Early diagnosis is extremely important from the prognostic point of view, because the allergic rhinitis can be the initial phase of more serious disease such as asthma. (Vignola,1998)

In the Czech Republic it was not classified as an occupational diseases until the Government Regulation No. 290/1995 Coll. establishing a list of occupational diseases, and which came into force on 1 January 1996. In Chapter III paragraph 10, there are listed allergic diseases of upper respiratory tract, if they occur at workplace, for which there is some evidence of exposure to dust or gaseous substances with allergenic effects. By definition, the professionalism of Chapter III/10 should be considered especially when diagnosing allergic rhinitis.

As occupational characteristics are considered either allergens occurring commonly in the environment, but in the workplace is their amount increased (flour in bakeries, grain dust in farming), or allergens, which are specific for certain industrial work environment (acid anhydrides in the production of plastics, platinum salts in galvanic works etc).

As in the case of occupational asthma when the professional formation of allergic rhinitis applied as high-molecular substances (animal and vegetable proteins, grain dust, insect antigens, latex, proteolytic enzymes) and low molecular weight compounds (diisocyanates, anhydrides of acids, substances contained in the rosin, antibiotics etc.)

\subsection{Etiopathogenesis of occupational rhinitis}

Repeated contact with professional allergen leads to IgE-dependent activation of mast cells in the nasal mucosa These cells produce mediators that are collected in their granules (histamine, tryptase). These mediators in conjunction with others (leukotrienes, prostaglandins, platelet activating factor, cytokines and others) cause vasodilatation and increased vascular permeability with edema, resulting in obscure in nasal passages. Increased secretion of glands produces mucous rhinorrhoea.

Stimulation of afferent nerve mediators can cause itchy nose, sneezing and in case of the local axonal reflex can also release neuropeptides that cause further mast cell degranulation. A characteristic feature of allergic inflammation is the local accumulation of inflammatory cells, including basophils and neutrophils, T lymphocytes and eosinophils, which was also involved in the cascade of immunopathological processes. (Mamessier et al.,2007, Braunstahl et al., 2000)

There is accumulating evidence that the workplace environment can induce or trigger a wide spectrum of rhinitis conditions involving immunological and nonimmunological mechanisms. (Castano et al, 2006) These various conditions should be referred to as a workrelated rhinitis and should be further distinguished according to the clinical features, etiopathogenic mechanisms and strength of evidence supporting the casual relationship. According to the revised nomenclature for allergy recently recommended by the European Academy of Allergy and Clinical Immunology (Johansson et al.,2001) and the classification of work-related asthma proposed by panels of experts, different types of work-related rhinitis may be delineated as summarized in Figure 1. (Moscato et al., 2008) 


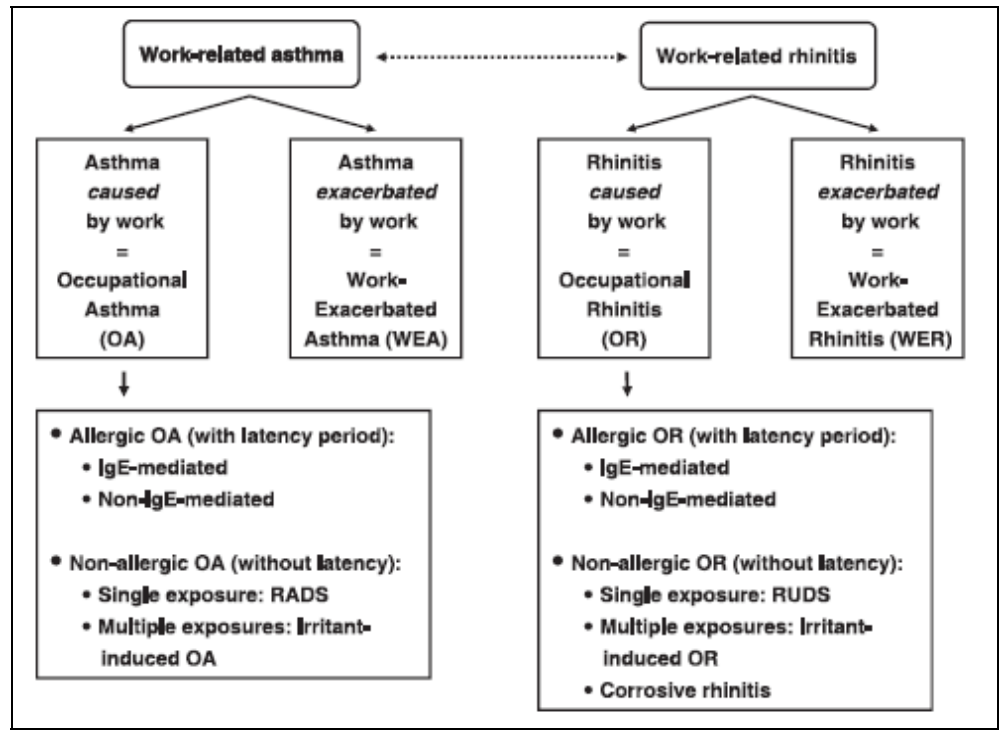

Fig. 1. Parallel classification of occupational rhinitis and asthma. RADS, reactive airways dysfunction syndrome; RUDS, reactive upper airways dysfunction symndrome

\subsection{The clinical picture of occupational disease}

Acute allergic rhinitis is defined as an inflammatory disease of the nasal mucosa, which occurs in response to airborne allergen occurring in the workplace.

The main symptoms are itching and irritation in the nose, sneezing and watery secretion, often associated with congestion of the nasal mucosa. It can be accompanied by itching in the throat, eyes and ears, which are often present symptoms of asthma.

Because this is a type I immune response, symptoms appear within minutes after the start of exposure and usually disappear within a short time after its completion. During the work week it usually causes deeper trouble. The improvement or disappearance of symptoms occur on weekends and holidays. (Storaas et al.,2005)

Depending on the amount of exposure and individual sensitivity, with some patients there may occur a late-phase allergic reaction within 6-12 hours that results in nasal hyperreactivity. This can be either specific (a specific allergen sensitization) or nonspecific (increased sensitivity to irritants that trigger an allergic reaction). As a by a professional unrecognized and untreated disease can rhinitis (after months or years) lead to chronicity.

Then the clinical picture is dominated by a sense of blocked nose and thick mucus. Sneezing and itching are infrequent or absent. They are observed in chronic conjunctive changes, swelling of eyelids, increased lacrimation. (Slavin, 2003)

\subsection{Complex diagnostic procedure}

A consensus diagnostic algorithm has been elaborated - see Fig 2 (Moscato et al, 2008) - by taking into account the following practical constraints:

a. the validity of tests used for diagnosing remains largely uncertain and

b. the level of reliability may vary according to the purpose of the diagnostic evaluation and its expected socio-economic impact. 


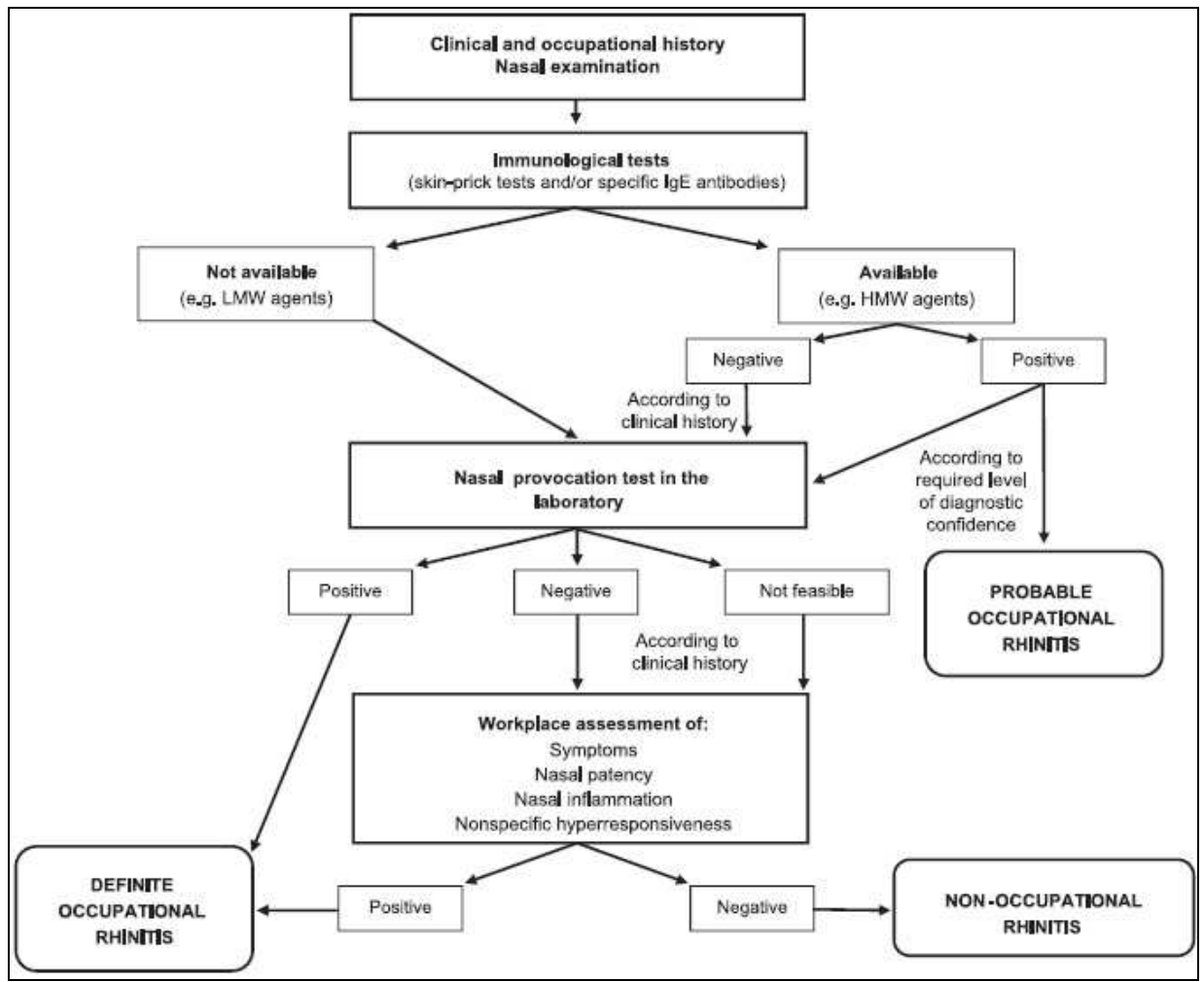

Fig. 2. Diagnostic algorithm

Complex diagnosis procedure for suspected occupational allergic rhinitis must focus on several steps:

1. History: (presence of clinical symptoms linked to the workplace): i.e. clinical symptoms, the onset of the first difficulties related to working environment, the total length of exposure to the noxa in the workplace, the current presence of breathing problems, other allergic manifestations with or without a link to the work environment, the incidence of allergic disease in the family.

2. ENT examination: it includes a front and rear rhinoscopy, nasal pathology exclusion type of nasal septum deviation, nasal polyps, foci, and the state of the nasal mucosa. A finding of pale, swollen mucous membrane is evident with the allergic rhinitis outside the period of manifest clinical signs.

3. Allergy tests: it includes intradermal skin or pointed-tip (SPT) tests, determination of serum total IgE, determination of allergen-specific IgE in serum by ELISA.

4. Bacteriological examination of swabs and nasal and throat: cytological analysis in allergic rhinitis is considered a pointer to increase the number of eosinophils.

5. X-ray paranasal sinuses and chest.

6. Blood tests: blood count with leukogramem, erythrocyte sedimentation rate.

7. Rhinomanometrie: measures the resistance of the nasal passages using quantitative measurement of nasal flow and pressure. Usually, front rhinomanometrie is used. A 
finding of pale, swollen mucous membrane is evident with the allergic rhinitis outside the period of manifest clinical signs.

8. Nasal provocation tests: these tests are still considered the gold standard for confirming the diagnosis of occupational rhinitis allergica. Nasal provocation tests can be performed either under controlled conditions in a laboratory or under natural conditions at work. (Airaksinen et al., 2007). These are methods that can be used to deliver occupational agents and to measure nasal response during nasal provocation tests.

\subsection{Assessment of occupational rhinitis allergica}

Next to the typical history, the clinical picture and a specific immune response are crucial to assess occupational rhinitis allergica. Nasal provocation tests with suspected inhalation of workplace noxa are the best possibility for objectification.. Nasal provocation tests have confirmed a causal relationship between the induction of symptoms and exposure to inhaled allergens in the workplace.

The most important aspect of the nasal provocation test is a comparison of objective and subjective parameters of patient's discomfort before and after nasal provocation. (Arandelovic et al.,2004)

There are provided objective evaluations of the decrease in nasal flow values (significant for the allergic reaction is a decrease of $-40 \%$ or more compared to the native value) and of the rise of resistance value (significant for the allergic reaction is a rise of $+60 \%$ or more compared to the native value)

Subjective difficulties are assessed according to a symptom score (see Table 1). Clinical symptoms assess as positive when reaching a total sum of at least 4 points or more.

\begin{tabular}{|l|l|l|}
\hline Symptoms: & Intensity: & Scoring \\
\hline Nasal Secretion & Without (Nothing) & 0 \\
\hline & Low (Medium) & 1 \\
\hline & Lot of (Significant) & 2 \\
\hline Sneezing & $0-2$ & 0 \\
\hline & $3-5$ & 1 \\
\hline & $>5$ & 2 \\
\hline Eyes Watering & & 1 \\
\hline Itching Palate & & 1 \\
\hline Itching Ears & & 1 \\
\hline Conjuntivitis & & 2 \\
\hline $\begin{array}{l}\text { Chemosis (swelling of the } \\
\text { conjuctiva) }\end{array}$ & & 2 \\
\hline Urticaria & & 2 \\
\hline Cough & & 2 \\
\hline Dyspnoea & & 2 \\
\hline
\end{tabular}

Table 1. Nasal symptom score 


\subsubsection{The procedure for nasal provocation tests}

First the patient must be informed about the nature of examinations - about examination procedure and duties assigned to it in the test result.

During testing, we follow the basic contraindications and take into account other important factors:

a. Contraindications:

- Acute inflammatory diseases of paranasal sinuses

- Nasal acute allergic-type reactions quickly manifest in other organs

- Patients with a higher degree of sensitivity - based on skin tests or IgE

- Pregnancy

- $\quad$ Ongoing vaccination against influenza

b. Other:

- $\quad$ any signs of nasal obstruction

- anatomical deformities (septal deviation, nasal polyps)

- last alcohol consumption at least 24 hours ago

- consumption of hot beverages (including coffee and tea) and food

- smoking

- elimination of nasal medication, if the patient's condition allows it

c. Recommendations for withdrawal therapy before the test:

- Nasal corticosteroids and nasal drops (Avamys etc.) - at least 3 days prior to the examination

- Corticosteroids (Prednisone, Beclomet, Pulmicort, etc.) - at least 3 days before testing

- Antihistamines (Zyrtec, Clarinin etc.) - at least 3 days prior to the examination

- Sodium cromoglycate, ketotifen (Zaditen) - at least 2 days before testing

- Xantin derivatives (Syntophylin, Euphylin) - 1-2 days prior to the examination

- Inhaled anticholinergics (Atrovent, Berodual) - at least 8-12 hours before testing

- Inhaled beta2 agonists (Berotec, Ventolin) - at least 6-8 hours before testing

Tests can be performed earlier than 6 weeks after abatement of symptoms of upper respiratory tract inflammation, at least 4 weeks after application of anti-influenza vaccine.

\section{Nasal provocation tests include}

\section{Native patient examination}

Firstly, the native rhinomanometric curve is recorded. According to the European Commission recommendations for standardization in rhinomanometry, only nasal active front rhinomanometry is used and a reference value is measured at a pressure of $150 \mathrm{~Pa}$. It is based on the principle of transnasal pressure and nasal resistance, which is then calculated from the nasal flow and transnasal pressure. The relationship between pressure and flow is a complex function of changing the turbulent air flow and the relationship between pressure and flow. (Guideline, 2008) the beginning of this test, eartips of olive-sized amount are inserted into the patient's nose, which correspond to anatomical dimensions of the nostrils, so that the exhaled air is not escaping out of olives. An olive with pressure sensor is inserted into the nostril of examined nasal cavity and a nasal flow is then recorded from the second nasal cavity. Then the nostrils are changed.

At Occupational Medicine Clinic at St..Anne in Brno ZAN 100 Handy device is used for the rhinomanometry examination. (See Picture 1.) 


\section{Application of control saline}

Nasal mucosa is exposed to the physiological solution, which excludes non-specific nasal hyperreactivity. The rhinomanometry curve is recorded.

\section{Custom nasal provocation}

In occupational medicine, there are a wide range of potential etiological agents. First we use nonspecific methacholine nasal provocation test. Positive test tells us that there is a reaction of the nasal mucosa and we can proceed to further investigations of the causal nox itself.

4. Nasal provocative test perform the following alternatives:

a. Simulated reexposive test with a suspicious noxa from the workplace:

We test only those substances that the patient was actually exposed to in the workplace. The patient is situated in a closed cabin, where he/she is manipulating with the material for 30 minutes at the most, like in the workplace.

b. Reexposive test directly in the workplace:

We test only in that environment, in which the patient was exposed. The test is performed during normal working hours.

After the end of the provocation, we record another rhinomanometry curve and evaluate nasal symptom score. The patient must be monitored for at least 24 hours to record also delayed responses.

\section{Rating of nasal provocation tests:}

The test is positive when the nasal resistance increases by $60 \%$ or more, and the nasal flow decreases by $40 \%$ or more, compared with values after application of control solution. (See Picture 2.)

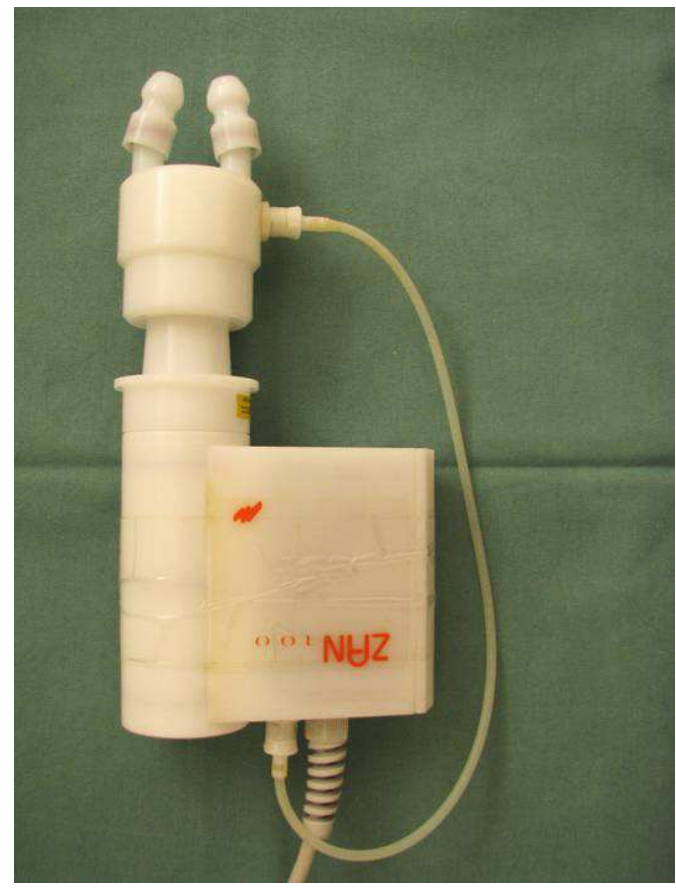

Picture 1. ZAN 100 Handy Device 


\subsection{Differential diagnosis}

It is necessary to distinguish the differential diagnosis of allergic rhinitis from other occupational allergic of different etiology, particularly seasonal allergic rhinitis, perennial rhinitis, infectious rhinitis, and others (idiopathic, irritation, hormonal, drug-induced, alimentary, psychogenic etc.)

It is also necessary to take in account other pathological processes in the nasal cavity, paranasal sinuses and secondary processes (polyps, mechanical changes, tumours, granulomas, cerebrospinal fluid). (Horwath et al, 1999)

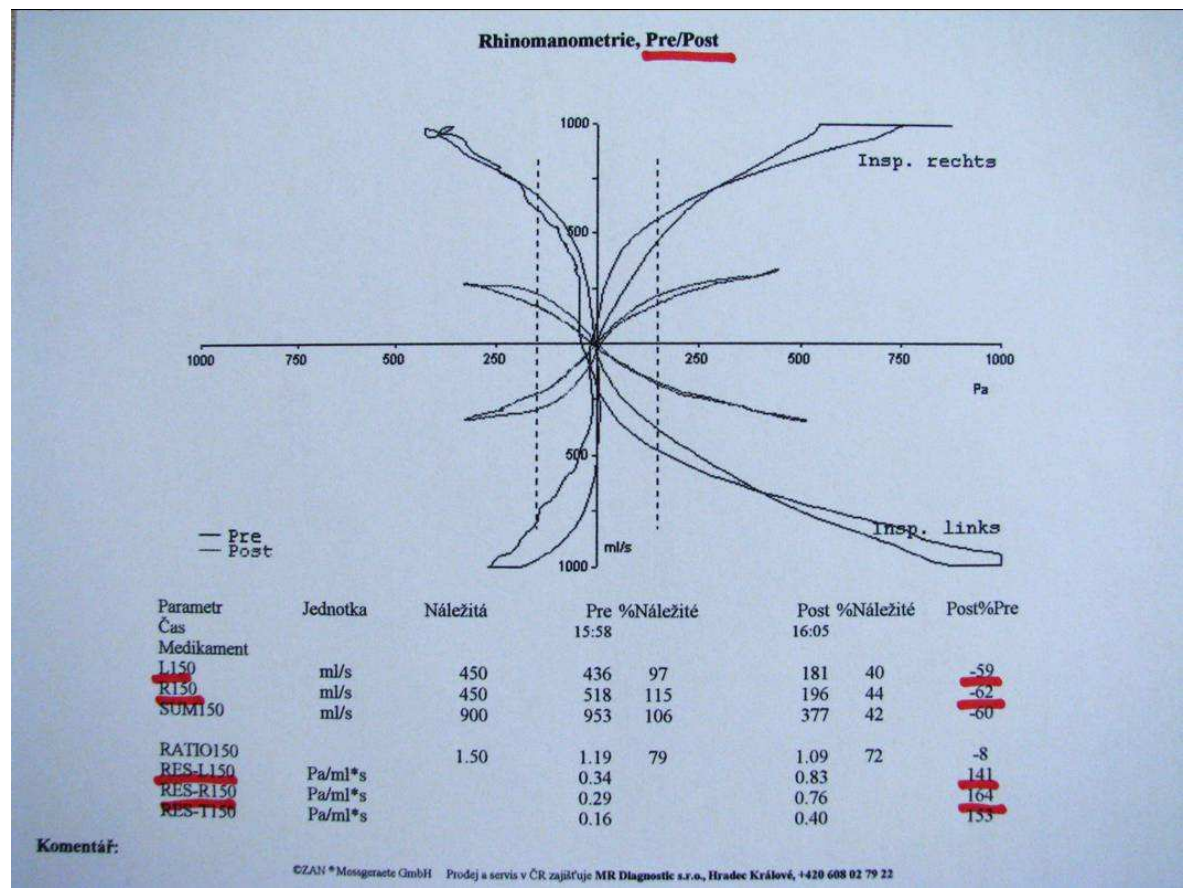

Picture 2. Rating of Nasal Provocation Test

\subsection{Treatment of occupational allergic rhinitis}

The basic essential step is the permanent removal of patient contact with the allergen professional. Drug treatment is identical to the unprofessional treatment of allergic rhinitis it means antihistamines, local eventually systemic corticosteroids. As the mast cell stabilizer disodium cromoglycate is used, you can also use anticholinergics, which absorb watery rhinorrhea but have no effect on nasal obscuration.

\subsection{Special precautions}

In terms of technical measures, it should be ensured that the permissible exposure limits at workplaces are not. There should be preferred safe technological processes and they should be preceded by emergency conditions. In case of high-risk procedures, the protection respirators should be ensured. 
Furthermore, patients with allergic rhinitis should not be working in the environment with a presence of known professional allergens and involvement of atopic in such operation should be carefully considered.

\section{Cases of occupational rhinitis allergica in southern Moravia}

\subsection{Examined group and methods}

There were analyzed all the cases of occupational rhinitis, which have been recognized and reported to the Occupational Medicine Clinic Hospital St. Anne in Brno and the Faculty of Medicine at the Masaryk University in Brno in the period from 1.1.2004 to 31.12.2006.

The statistical analysis was performed using Microsoft Office Excel and Statistica for Windows. Considering the lack of data normality, we used nonparametric tests.

\subsection{Results}

During the reporting period 86 cases of occupational rhinitis were diagnosed and reported. Of this group, 59 (68.6\%) were women and 27 (31.4\%) men. The median age (median) of the whole group at the time of notification of occupational disease was 39.5 years, age range was wide, it varied from 19 to 63 years. (See Table 2, 3 and 4)

\begin{tabular}{|l|c|c|c|}
\hline Parameter & Women (n=59) & Men (n=27) & Total (n=86) \\
\hline Age (Years) & 40,4 & 35,2 & 38,7 \\
\hline Mean & 10,8 & 9,96 & 10,8 \\
\hline SD & 42 & 32 & 39,5 \\
\hline Median & 19 & 23 & 19 \\
\hline Min. & 63 & 63 & 63 \\
\hline Max. & \multicolumn{5}{|l|}{} \\
\hline Exposure (Years) & 8,8 & 10,46 & 9,32 \\
\hline Mean & 7,24 & 8,06 & 7,5 \\
\hline SD & 7 & 8 & 7 \\
\hline Median & 0,83 & 2 & 0,83 \\
\hline Min. & 30 & 27 & 30 \\
\hline Max. & & & \\
\hline
\end{tabular}

$\mathrm{n}=$ the amount of patients, $\mathrm{SD}=$ standard deviation, $\min .=$ lowest value, $\max .=$ highest value

Table 2. Basic Group Data

Mean duration of exposure to etiological noxa (median) was 7 years, duration of exposure varied from 0.83 to 30 years. (See Table 5).

We also investigated the time elapsed since the first manifestation of symptoms of rhinitis to recognition of occupational disease, the median was 1 year (see Table 3).

There was no statistically significant difference among women and men (Mann-Whitney's U test, $\mathrm{p}>0.05)$ in any of the parameters mentioned above. 


\begin{tabular}{|l|c|c|c|}
\hline Parameter & Rhinitis (n=40) & $\begin{array}{c}\text { Rhinitis } \\
\text { and Astma (n=46) }\end{array}$ & Total (n=86) \\
\hline Age (Years) & \multicolumn{5}{|l|}{} \\
\hline Mean & 36,6 & 40,6 & 38,7 \\
\hline SD & 10,2 & 10,8 & 10,8 \\
\hline Median & 37 & 41,5 & 39,5 \\
\hline Min. & 19 & 22 & 19 \\
\hline Max. & 57 & 63 & 63 \\
\hline Exposure (Years) & \multicolumn{4}{|l|}{} \\
\hline Mean & 8,1 & 10,4 & 9,32 \\
\hline SD & 6,4 & 8,1 & 7,5 \\
\hline Median & 5,5 & 8 & 0,83 \\
\hline Min. & 0,83 & 1 & 30 \\
\hline Max. & 23 & 30 & 1,44 \\
\hline The Duration of Symptoms to the Notification of Occupational Disease (Years) \\
\hline Mean & 1,17 & 1,68 & 1,01 \\
\hline SD & 0,69 & 1,17 & 1 \\
\hline Median & 1 & 1,75 & 7,33 \\
\hline Min. & 0,33 & 0,33 & 7 \\
\hline Max. & 3 & & \\
\hline
\end{tabular}

$\mathrm{n}=$ the amount of patients, $\mathrm{SD}=$ standard deviation, $\min .=$ lowest value, max. = highest value

Table 3. Next Group Data

Professions, in which the affected were employed are summarized in Table 6. The work in bakeries, textile industry and livestock production prevailed. Rye or wheat flour and textile fibres (cotton, wool, synthetics are usually applied as professional etiological agents ), others included different feed mixtures, wood dust, straw, preservatives, varnishes and adhesives.

\begin{tabular}{|l|c|c|c|c|}
\hline Age (Years) & Women (n) & Men (n) & Total (n) & $\mathbf{\%}$ \\
\hline $\mathbf{1 5 - 1 9}$ & 1 & 0 & 1 & 1,2 \\
\hline $\mathbf{2 0 - 2 4}$ & 4 & 1 & 5 & 5,8 \\
\hline $\mathbf{2 5 - 2 9}$ & 9 & 8 & 17 & 19,8 \\
\hline $\mathbf{3 0 - 3 4}$ & 4 & 8 & 12 & 13,9 \\
\hline $\mathbf{3 5 - 3 9}$ & 6 & 2 & 8 & 9,3 \\
\hline $\mathbf{4 0 - 4 4}$ & 12 & 4 & 16 & 18,6 \\
\hline $\mathbf{4 5 - 4 9}$ & 10 & 0 & 10 & 11,6 \\
\hline $\mathbf{5 0 - 5 4}$ & 9 & 3 & 12 & 13,9 \\
\hline $\mathbf{5 5 - 5 9}$ & 4 & 0 & 4 & 4,7 \\
\hline $\mathbf{6 0 - 6 4}$ & 0 & 1 & 1 & 1,2 \\
\hline Total & $\mathbf{5 9}$ & $\mathbf{2 7}$ & $\mathbf{8 6}$ & $\mathbf{1 0 0}$ \\
\hline
\end{tabular}

$\mathrm{n}=$ the amount of patients

Table 4 . Distribution by age at the time of notification of occupational disease 


\begin{tabular}{|l|c|c|}
\hline Exposure (Years) & Amount of Patients & \% \\
\hline do $\mathbf{2 , 9}$ & 13 & 15,1 \\
\hline $\mathbf{3 , 0 - 5 , 9}$ & 23 & 26,7 \\
\hline $\mathbf{6 , 0 - 8 , 9}$ & 14 & 16,4 \\
\hline $\mathbf{9 , 0 - 1 1 , 9}$ & 11 & 12,9 \\
\hline $\mathbf{1 2 , 0 - 1 4 , 9}$ & 5 & 5,8 \\
\hline $\mathbf{1 5 , 0 - 1 7 , 9}$ & 5 & 5,8 \\
\hline $\mathbf{1 8 , 0 - 2 0 , 9}$ & 3 & 3,5 \\
\hline $\mathbf{2 1 , 0 - 2 3 , 9}$ & 7 & 8,1 \\
\hline $\mathbf{2 4 , 0 - 2 6 , 9}$ & 3 & 3,5 \\
\hline $\mathbf{2 7 , 0 - 2 9 , 9}$ & 1 & 1,1 \\
\hline $\mathbf{3 0 , 0}$ and more & 1 & 1,1 \\
\hline Total & $\mathbf{8 6}$ & $\mathbf{1 0 0}$ \\
\hline
\end{tabular}

Table 5. Distribution by the length of exposure to etiological noxa

\begin{tabular}{|l|c|}
\hline Profession & Number of occupational diseases \\
\hline Baker & 29 \\
\hline Worker in a bakery & 9 \\
\hline Milkmaid & 8 \\
\hline Seamstress & 5 \\
\hline Dressmaker & 5 \\
\hline Confectioner & 3 \\
\hline Repairman & 3 \\
\hline Nurse & 2 \\
\hline Cabinetmaker & 2 \\
\hline Printer & 2 \\
\hline Painter & 2 \\
\hline Cook & 2 \\
\hline Electrician & 2 \\
\hline Worker in Production of Compound Feed & 1 \\
\hline Workers in Pasta Plant & 1 \\
\hline Worker in Chemical Industry & 1 \\
\hline Developer & 1 \\
\hline Worker at Service Lines & 1 \\
\hline Worker at mill & 1 \\
\hline Worker in army & 86 \\
\hline Total & \\
\hline & \\
\hline
\end{tabular}

Table 6. Distribution according to profession 
At the time of reporting rhinitis allergica as an occupational disease, 46 of 86 probands - $54 \%$ of the sample - had currently suffered with bronchial asthma.

The basic time parameters in a group of patients with rhinitis were compared to a group of patients also affected by bronchial asthma. When comparing the median length of exposure and the median time of the first manifestations of nasal symptoms in the recognition of occupational disease, we can see that in the group, where there was reported only rhinitis, the exposure of noxa symptoms and their length of shorter than with those with asthma. (See Table 3) However, the differences observed were not statistically significant (MannWhitney's U test, $\mathrm{p}>0.05$ ).

We were also interested in the number of smokers in the examined group. $18.6 \%$ of probands of the sample smoked cigarettes at the time of recognition of occupational disease, $72.1 \%$ patients were non-smokers and the rest of probands $(9.3 \%)$ were former smokers.

We compared the value of symptom scores at the time of recognition of occupational diseases with the value acquired the year after the recognition of occupational disease. Symptom score was evaluated by adding the points according to Table 1.

Table 7 shows a statistically significant (Wilcoxon paired test, $\mathrm{p}$-value $\mathrm{p}<0,001$ ) decrease of symptom score at the time of recognition of occupational disease compared with symptom score one year after rhinitis has been recognized as an occupational disease.

\begin{tabular}{|l|c|c|c|}
\hline Parameter & Rhinitis (n=40) & $\begin{array}{c}\text { Rhinitis } \\
\text { and Asthma (n=46) }\end{array}$ & Total (n=86) \\
\hline Symptom score at the time of recognition of occupational disease \\
\hline Mean & 12,87 & 12,67 & 12,76 \\
\hline SD & 1,27 & 1,44 & 1,37 \\
\hline Median & 12 & 13 & 12,5 \\
\hline Min. & 11 & 10 & 10 \\
\hline Max. & 16 & 16 & 16 \\
\hline Symptom score - one year after the recognition of occupational disease & \\
\hline Mean & 4,71 & 4,75 & 4,73 \\
\hline SD & 0,8 & 0,92 & 0,87 \\
\hline Median & 5 & 5 & 5 \\
\hline Min. & 2 & 3 & 2 \\
\hline Max. & 6 & 7 & 7 \\
\hline
\end{tabular}

$\mathrm{n}=$ the amount of patients, $\mathrm{SD}=$ standard deviation, $\min .=$ lowest value, max. $=$ highest value

Table 7. Nasal Symptom score

When comparing individual items of the nasal symptom score, we came to the conclusion that even there was a statistically significant (Wilcoxon paired test, p-value $p<0,001$ ) decrease of each parts of symptom score. For details see Figure 3. 


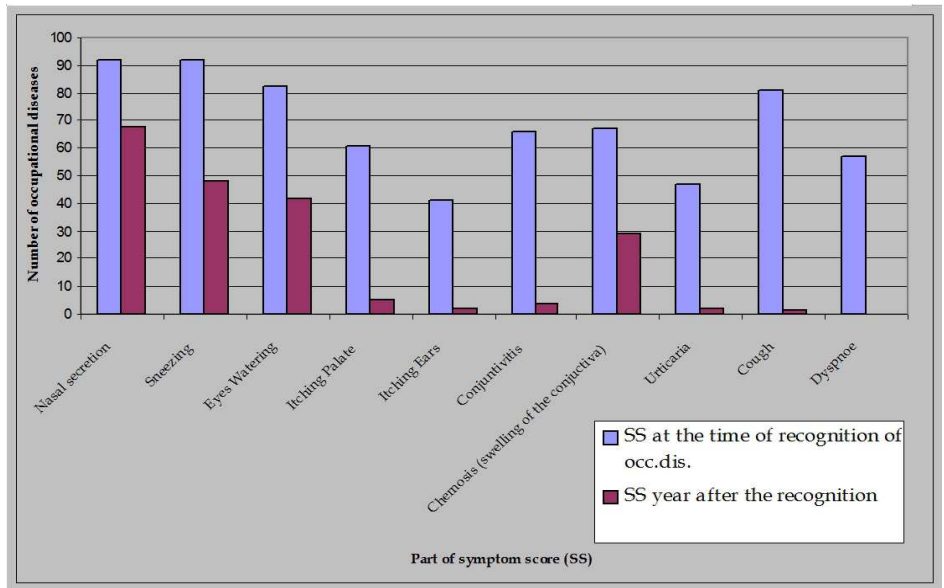

Fig. 3. Parts of symptom score

\subsection{Discussions}

Occupational rhinitis participated in the occupational diseases reported in southern Moravia between 2004 and 2006 in $7.2 \%$ of all the cases.

Compared with a period of years 1996 - 1999 (Brhel et al, 2000), there are no major changes. In both periods, there were more women in the group and the most common age of both groups are from 40 to 44 years. The overall average age is now slightly higher (38.7 versus 34.7 years).

Length of exposure necessary for developing the disease is now also slightly higher (median 7 versus 5), but not statistically significant (Mann-Whitney's U test, $p>0.05$ ).

The number of recognized diseases of occupational rhinitis has been gradually decreasing, not only at the Department of Occupational Diseases, St. Anne's Hospital and Masaryk University Brno, but also in the whole country, as shown in Figure 4.

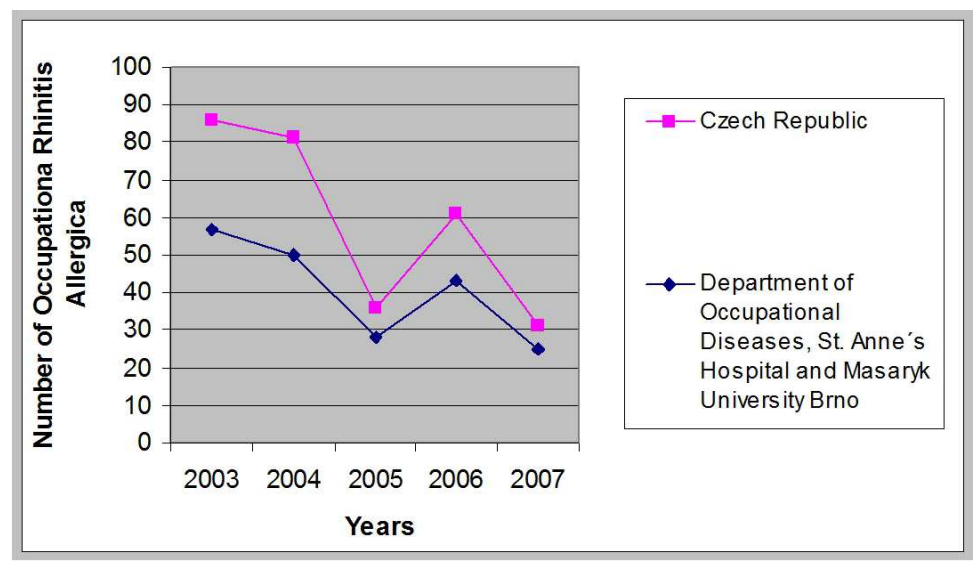

Fig. 4. Number of Occupational Rhinitis 
If we look at the etiological noxa and individual professions of occupational rhinitis now and in the past, there have been minor changes - there are the same professions, such as workers in bakeries, textile industry and livestock production.

When comparing the number of smokers, the data show that the number of smokers has decreased and we can consider it good news.

\section{Conclusion}

Allergic rhinitis occurs all over the world. We are spending many hours a day in the work environment, so it is necessary to monitor all inhaled allergens.

Nasal provocation tests assess the clinical relevance of sensitization verified skin or serological tests. Mostly we use tests in the test room at Departments of Occupational Medicine under controlled conditions - tests are performed only with substances that occur in the workplace. In some cases, also nasal provocation tests must be performed directly at the workplace.

Allergic rhinitis makes the quality of life significantly worse and it is often associated with other comorbidities. When we investigate occupational allergic rhinitis, we should always confirm the causal link between allergic rhinitis and working environment, so we must find etiological agents (noxa).

A careful history, occupational health knowledge, willingness to consider the causal link and following the recommended use of investigative procedures will enable early detection of occupational rhinitis.

After the recognition of occupational disease it is necessary to avoid the patient's contact with the causal noxa exposure. This avoids the potential for occupational development of asthma bronchiole and other related diseases that accompany chronic allergic rhinitis.

\section{References}

Airaksinen L. et al.: Use of nasal provocation test in the diagnostics of occupational rhinitis. Rhinology, 2007, 45, pp. 40-46.

Arandelovic M., Stankovic, I.: Allergic rhinitis-possible occupational disease-criteria suggestion. Acta Fac. Med. NAISS., 2004, 21, 2, pp. 65-71.

Bascom R., Shusterman D. Occupational and environmental exposures and the upper respiratory tract. In: Naclerio R. M., Durham S. R., Mygind N. (eds.). Rhinitis mechanisms and management. New York-Basel-Hongkong: Marcel Dekker Inc., 1999: p. 65- 99.

Braunstahl, GJ et al: Nasal provocation results in bronchial inflammation in allergic rhinitis patients. Am.J respir Crit Care Med 2000; 161: A, p. 325.

Brhel P.,Vomelová K., Říhová A.: Profesionální rinitida na jižní Moravě, Pracov. Lék., 52, 2000, 3, pp. 116-119

Castano R, Theriault G, Gautrin D., The definition of rhinitis and occupational rhinitis needs to be revisited, Acta Otolaryngol 2006: 126: pp.1118-1119

Cauwenberge van P., Bachert C., Passalacqua G., et al.: Consensus statement on the treatment of allergic rhinitis. Allergy, 55, 2000: pp 116-134

Guideline: Management of allergic rhinitis and its impact on asthma. Geneva (Switzerland): World Health Organization (WHO); 2008. 
Horwath P. H.: Mucosal Inflammation and Allergic Rhinitis. In: Rhinitis Mechanism and Management (Naclerio R. M., Durham S. R., Mygind N., eds.), Marcel Dekker Inc., New York-Basel-Hongkong, 1999: pp 109-133

Johansson SG, Hourihane JO, Bousquet J et al., A revised nomenclature for allergy. An EAACI position statement freom ESSCI nomenclaturetask force, Allergy 2001:56: pp 813-824

Mamessier E., Milhe F., Guillot C. et al.: T-cell activation in occupational asthma and rhinitis, Allergy, Oxford 2007. Vol. 62, 2, pp. 162-169

Moscato et al, Occupational Rhinitis, Allergy 2008:63: pp 969-980

Slavin R. G.: Occupational Rhinitis. Annals of Allergy, Asthma \& Immunology, 90,2003, 5, pp. 2-6

Storaas T. et al::Occupational rhinitis: diagnostic criteria, relation to lower airway symptoms and IgE sensitization in bakery workers. Acta Oto-Laryngologica, 2005, 125, pp. 1211-1217

Vignola A. M: Relationship between rhinitis and asthma. Allergy, 53, 1998: pp. 833-839 


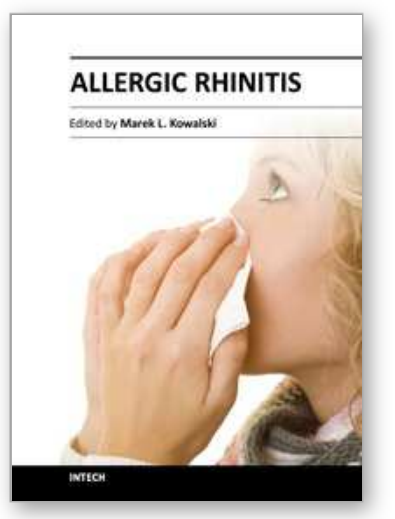

\author{
Allergic Rhinitis \\ Edited by Prof. Marek Kowalski
}

ISBN 978-953-51-0288-5

Hard cover, 214 pages

Publisher InTech

Published online 21, March, 2012

Published in print edition March, 2012

Allergic rhinitis, while troublesome for a patient, may be also a challenge for the physician. That is why physicians must still learn more on the pathophysiology, clinical spectrum and novel diagnostic and therapeutic approaches to the disease. The chapters of this volume address a variety of important topics related to allergic rhinitis. They begin with a description of innovative translational approaches allowing for unification of animal and human models. Contributing authors provide up-to-date reviews of clinical aspects of allergic rhinitis in children, its association with bronchial asthma and other co-morbid conditions. They also discuss the impact of allergic rhinitis on sleep and sports. Together with articles on diagnostic approaches as well as novel treatments, the book offers a comprehensive and stimulating review of the topic. May this book find a wide readership among allergists and other physicians interested in allergic disease, and also among pediatricians, general practitioners and other specialists who increasingly have to deal with this seemingly benign, but sometimes extremely troublesome, disease.

\title{
How to reference
}

In order to correctly reference this scholarly work, feel free to copy and paste the following:

Petr Malenka (2012). Occupational Allergic Rhinitis in the Czech Republic - Situation in South Moravia Region, Allergic Rhinitis, Prof. Marek Kowalski (Ed.), ISBN: 978-953-51-0288-5, InTech, Available from:

http://www.intechopen.com/books/allergic-rhinitis/occupational-allergic-rhinitis-in-czech-republic-the-situationin-south-moravia-region-

\section{INTECH}

open science | open minds

\section{InTech Europe}

University Campus STeP Ri

Slavka Krautzeka 83/A

51000 Rijeka, Croatia

Phone: +385 (51) 770447

Fax: +385 (51) 686166

www.intechopen.com

\section{InTech China}

Unit 405, Office Block, Hotel Equatorial Shanghai

No.65, Yan An Road (West), Shanghai, 200040, China

中国上海市延安西路65号上海国际贵都大饭店办公楼 405 单元

Phone: +86-21-62489820

Fax: +86-21-62489821 
(C) 2012 The Author(s). Licensee IntechOpen. This is an open access article distributed under the terms of the Creative Commons Attribution 3.0 License, which permits unrestricted use, distribution, and reproduction in any medium, provided the original work is properly cited. 